\title{
A OBRA DE HASSIS COMO SINTOMA DO SUJEITO DIALÉTICO, ENGEDRANDO NOVAS CONEXÕES FORA DE SEU ESPAÇO E TEMPO
}

\author{
Cláudia Silvana Saldanha Palheta \\ PPGAV/UDESC
}

\begin{abstract}
Resumo
Pensando sobre a sobrevivência da imagem, o artigo propõe a análise da obra "Vento sul com chuva" (1957), de Hassis (1926-2001), artista catarinense, a partir das articulações engendradas por ela. Buscou-se as contribuições de Didi-Huberman e Walter Benjamin no intuito de se compreender as imagens como sintomas de uma memória que é particular e historicamente construída, constelando a obra com outras duas de expressiva simbologia: a fotografia do paraense Luiz Braga e o desenho de catarinense Susano Correia. O modo de estar e perceber o mundo, influenciaram, sobremaneira, a trajetória artística de Hassis, que passou a vida organizando e reorganizando imensurável arquivo de suas obras; objetos e documentos (hoje preservados pelo Instituto Hassis), que só tem significado se entendermos sua obra, enquanto imagem, como sintoma da relação dialética do próprio artista em seu espaço e tempo.
\end{abstract}

\section{Palavras-chave:}

Hassis; Vento sul com chuva; arquivo.

\section{ARQUIVO HASSIS}

No cenário artístico catarinense, entre a década de 1940 e o início do século XXI, Hassis figurou como um dos artistas mais atuantes. Dono de uma extensa produção, suas obras percorreram os mais diversos estilos artísticos, mas sempre imprimindo uma marca muito particular. Ao escrever sobre o artista em sua tese "Mito e Magia na Arte Catarinense", a crítica e historiadora de arte Adalice Maria de Araújo registrou em 1977: "Saindo de uma pintura documental, com passagens pelo fauvismo, expressionismo, popart, concretismo - foi no decorrer do tempo penetrando numa atmosfera surreal, nascida sob a égide de um telurismo crítico." (ARAÚJO, 1977,

\section{Abstract}

Thinking about the survival of the image, the article proposes the analysis of the work "South Wind with Rain" (1957), by Hassis (1926-2001), a Santa Catarina artist, based on the articulations engendered by it. The contributions of DidiHuberman and Walter Benjamin were sought in order to understand the images as symptoms of a memory that is particular and historically constructed, constellating the work with two others of expressive symbology: the photograph of the Paraense Luiz Braga and with the drawing by Susano Correia, artist from Santa Catarina.The way of being and perceiving the world, influenced, the artistic trajectory of Hassis, who spent his life organizing and reorganizing the archive of his works; objects and documents (now preserved by the Hassis Institute), which is meaningful only if we understand his work as an image, as a symptom of the artist's dialectic relation in space and time.

Keywords:

Hassis; South wind with rain; archive.

p. 211). De lá, até sua morte, em 2001, Hassis experimentou mais uma infinidade de estilos, linguagens, técnicas e suportes artísticos, na busca incansável por uma autonomia criativa. No contexto da época, tornou-se um dos pioneiros da pop-art no sul do país e marcou seu nome entre os mais importantes artistas muralistas nacionais. (ARAÚJO, 1977).

Artista múltiplo, além de pintor autodidata, Hassis transitou, em diferentes épocas, pelo desenho, escultura, fotografia, cinema; ilustrou capas de revistas e livros, desenhou cartazes, atuando em "publicidade, símbolos, logotipos, cartazes, capas de revistas e livros", segundo a historiadora de arte Sandra Makowiecky (2012, p. 210). 


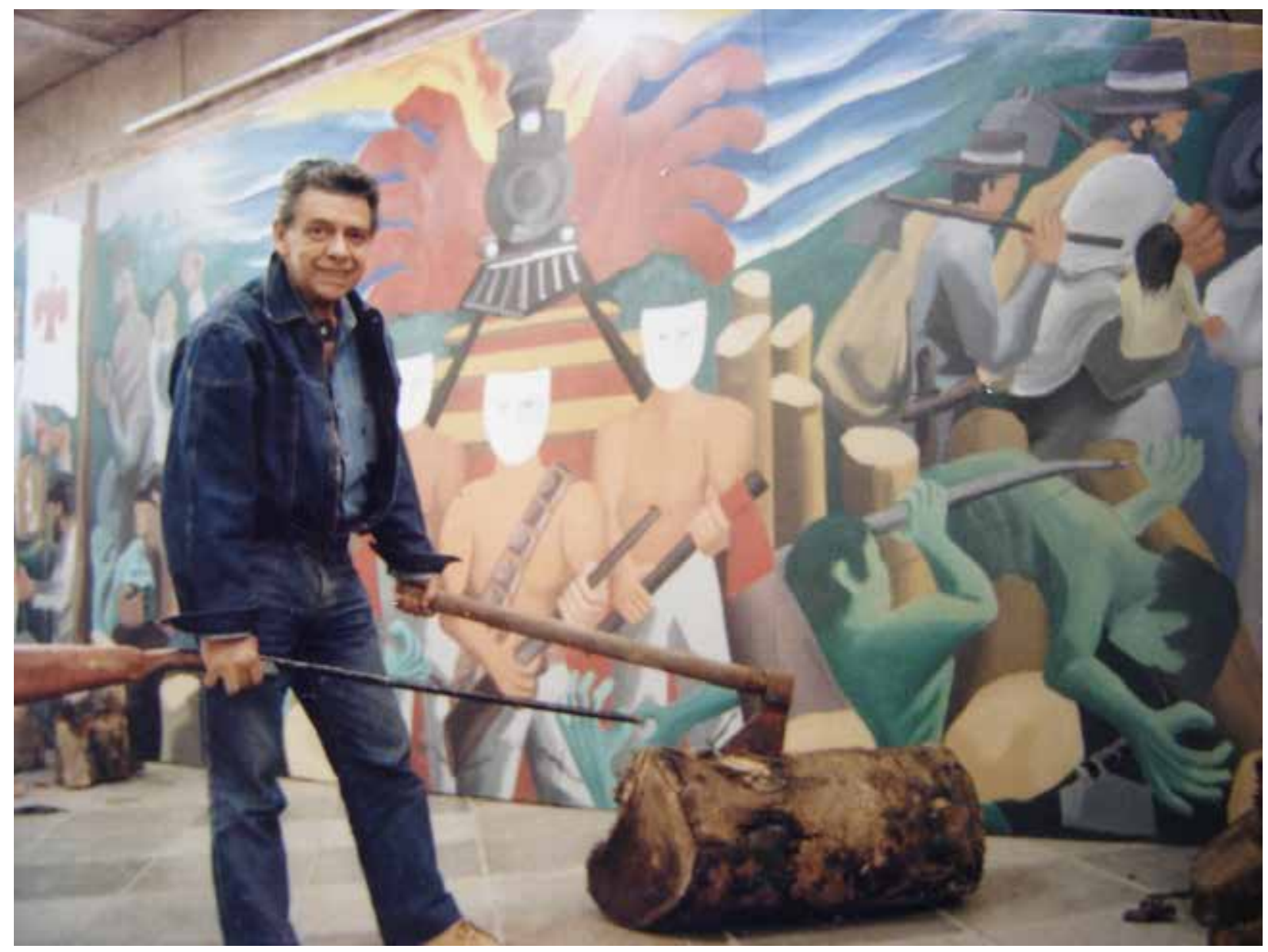

Figura 1 - Hassis e o Painel da Guerra do Contestado. Fonte: Site da Fundação Hassis

Foi também experimentando as mais variadas técnicas e suportes expressivos, como o nanquim, a aguada, o grafite, pintura em guache, óleo, acrílica, colagens, papel, papelão, madeira, tela, compensado, entre outros, que Hassis, então, introduziu a pop-art na cena artística catarinense. (MAKOWIECKY, 2012). (Figura 1).

Hassis não nasceu em Florianópolis, tampouco nasceu Hassis. Seu nome de batismo foi se modificando na medida em que este se auto afirmava como artista. "De Hiedy de Assis Corrêa, passou a H. Assis Corrêa, depois H. Assis, para resumir-se a Hassis"1. Filho de Orlando de Assis Corrêa, natural de Curitiba/PR, sargento do Exército Nacional, e de Laura Rodrigues Corrêa, de Santo Amaro da Imperatriz/SC, Hassis nasceu em Curitiba, em 1926, devido a itinerância militar de seu pai, que, sendo do Exército, foi transferido de Florianópolis para Curitiba em 1925. Mas foi em Florianópolis que passou todo o restante de sua vida, quando a família, após sucessivas mudanças, finalmente retornou e se fixou na cidade, em 1928, quando Hassis estava então, com dois anos de idade. Em 1950, após a morte do pai, Hassis passou a sustentar a casa e os irmãos menores, indo residir no centro da cidade, período em que conheceu Nazle Paulo, que viria a ser sua companheira ao longo de toda a sua vida.

Em 1948, foi convidado para ilustrar o conto "Flores" e a capa do livro "Terra Fraca". Depois, ilustrou o conto "Noturno", tornando-se ilustrador da Revista Sul, passando a contribuir com o movimento literário e artístico conhecido por "Grupo Sul", nas década de 40 e 50. Entre 1961 a 1987, Hassis faz a decoração de carnaval nos principais clubes da cidade. Em 1965 criou desenhos em mosaico português, para cinco praças públicas de Florianópolis, referenciando o folclore ilhéu, participou de aproximadamente 213 coletivas e salões entre Santa Catarina, 
Paraná, São Paulo e Rio Grande do Sul. Foram mais de 66 exposições individuais realizadas. Suas obras integram o acervo dos seguintes Museus de Arte: MASC de Florianópolis/SC, MAC de Curitiba/PR, além de coleções particulares no Brasil e no exterior.

A vasta biografia do artista, é lembrada em praticamente todos os registros encontrados sobre o trabalho de Hassis, seja em artigos, livros, dissertações ou teses, é possível notar a relevância dada a sua biografia nas análises acerca de sua produção, desde o seu nascimento até sua morte, em 2001. Atribui-se a este fato a importância dada pelo próprio artista, que ao longo de sua vida preocupou-se em organizar, registrar e arquivar de forma minuciosa e sistemática tudo que considerava relevante de sua própria vida, de seu lugar e de seu tempo, facilitando sobremaneira o trabalho de pesquisadores.

O pesquisador de arte Fernando Chíquio Boppré, que pesquisou e escreveu sobre a vida e obra de Hassis, explica que a importância desse "esboço biográfico" sobre o artista permite "situá-lo geográfica e historicamente." (BOPPRÉ, 2006, p. 376). De modo que conhecer sua história de vida, suas passagens, afetividades e influências, como também seu "modus operandi", no que se refere à forma com que ele próprio organizava e selecionava suas memórias e as arquivava, como se deixasse pistas de como gostaria de ser lembrado no presente, permite-nos compreender hoje, não apenas e meramente aspectos de sua vida privada, mas sobretudo, sua trajetória artística, suas referências e seus percursos criativos, entendendo como os fatos relevantes de sua vida pessoal e suas impressões de mundo o construíram artisticamente. Esse modo de "operar", de ser e estar no mundo, diz muito de como o artista percebe a si próprio e as coisas do mundo e os transmuta em um estilo muito particular de trabalho. Diz Boppré:

A multiplicidade e quantidade de documentos reunidos é, deste modo, um dos principais aspectos de Hassis. Sua casa, onde todo o rés-do-chão abrigava o ateliê, era uma verdadeira reunião de espaços e tempos. Fragmentos reunidos de forma sistematizada, sempre contendo a referência temporal e autoral. Ao se deparar com o ateliê de Hassis, a primeira impressão é que há ali um universo todo-próprio, um tempo cuidadosamente recolhido e organizado. (BOPPRÉ, 2006, p. 377)
Assim, além do conjunto das obras, incansavelmente organizadas e reorganizadas por Hassis, também configuram o seu arquivo, no ateliê que hoje abriga a Fundação Hassis, inúmeros objetos pessoais, como livros, catálogos e convites de exposições, capacetes de guerra, rádios, rolos de filmes cinematográficos, jornais, fotografias, negativos, slides, filmes de Buster Keaton, Chaplin, Tarzan, King Kong, Flash Gordon e documentários sobre a Segunda Guerra. Para Boppré, essa forma de recolher objetos diversos se traduz numa "tentativa de apreensão do tempo" (BOPPRÉ, 2006, p.377). Pode-se entender, nesse sentido, o arquivo de Hassis como montagens de espaços e tempos; constelações particulares criadas por ele, que embora remontem o passado, é o presente que acabam por revelar e é, sobretudo, ao presente que servem.

Tentando compreender como operam os arquivos de artistas, encontrou-se em Rosângela Cherem, em artigo apresentado na Anpap de 2016, a seguinte reflexão:

(...) pode-se considerar que todo arquivo é ímpar,
na medida em que se relaciona ao repertório
visual e conceitual, seja plástico ou teórico,
ficcional ou documental que cada artista traz e
processa no interior de seu trabalho como índice
de um pensamento em constante experimentação.
Assim, cada artista é portador de um sistema de
enunciados e imagens no qual incidem referências e
memórias, sensibilidades e habilidades, construções
poéticas e soluções matéricas, noções operatórias,
alternativas de fatura, etc. (CHEREM, 2016, p.1201)

Dessa forma, é possível entender os arquivos de Hassis como uma espécie de "sítio arqueológico" e assim, suas obras se constituiriam como enunciados de seu arquivo. Viviane Trindade Borges, escreveu sobre o processo de arquivamento de Hassis:

O trabalho de arquivamento de si operado por Hassis através de diferentes registros e suportes, como as entrevistas arquivadas, possibilita pensar questões ligadas à autobiografia, ao enquadramento e desejo de memória, bem como às escritas de si. Conforme mencionado anteriormente, Hassis não deixou documentos escritos, mas pode-se supor que o personagem operou um trabalho de registro pessoal através de diferentes suportes. Esses documentos, ainda pouco explorados, permitem pensar os limites e possibilidades oferecidos ao homem ordinário como suportes para contar sua vida. (BORGES, 2011, p. 46-47)

Makowiecky ressalta que a importância de Hassis no contexto da arte catarinense se dá em razão 


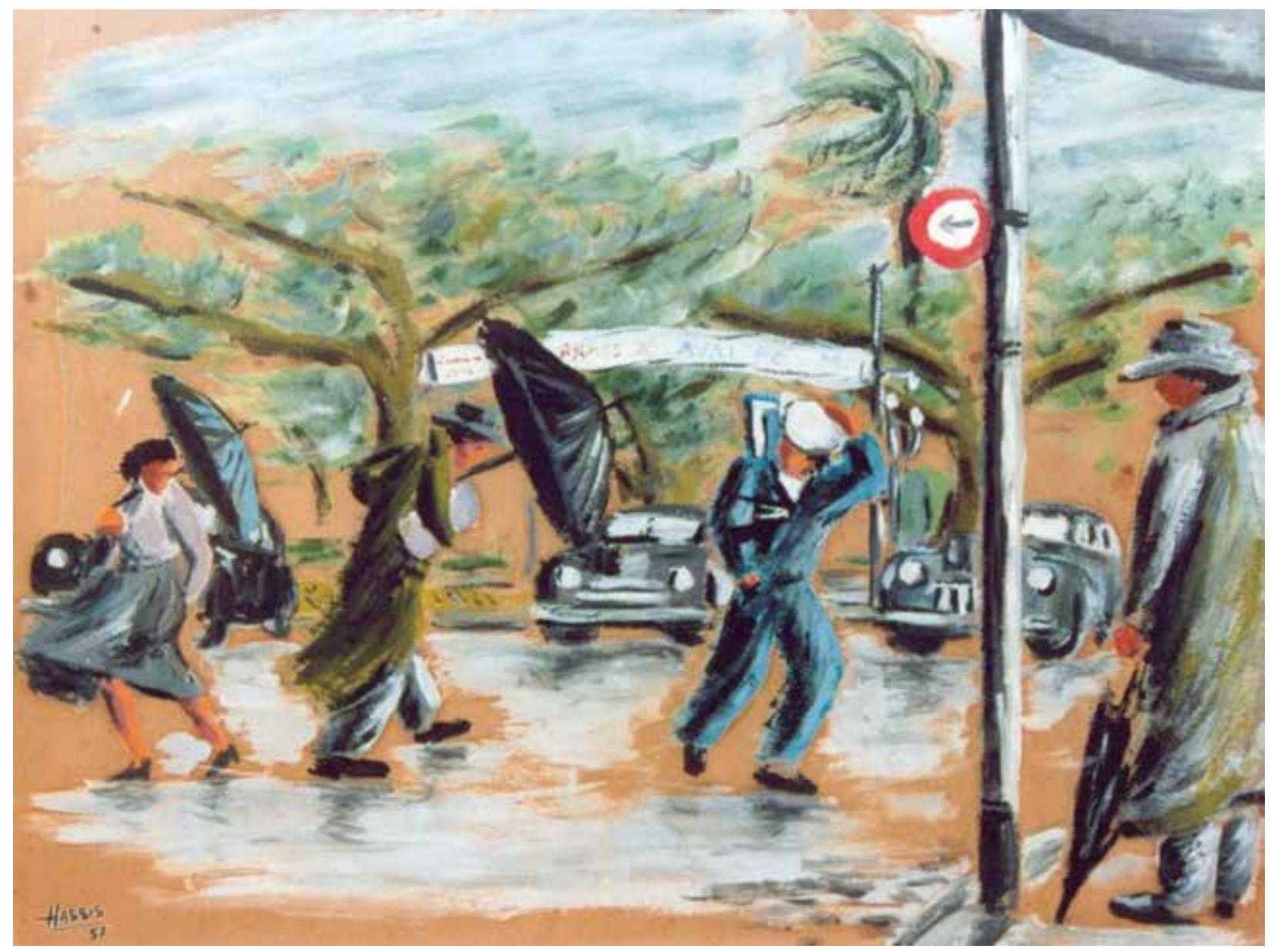

Figura 2 - Chuva na Praça da Sereia. Fotografia. Luiz Braga. 1995. Fonte: Estúdio Luiz Braga.

de "ter inovado a linguagem das artes plásticas no Estado, junto ao pintor Meyer Filho, na inauguração da sede do Instituto Brasil - Estados Unidos com a exposição 'Primeira Exposição de Pinturas e desenhos de Motivos Catarinenses'." (MAKOWIECKY, 2012, p. 210). Além disso, ele foi membro fundador do Grupo de Artistas Plásticos de Florianópolis (GAPF), participando do primeiro salão promovido pelo grupo, em 1958, ocasião em que ganhou o primeiro lugar com a obra "Vento sul com chuva", uma das pinturas mais emblemáticas desse fenômeno natural característico e marcante do cotidiano catarinense, da qual falaremos mais adiante. Os críticos e historiadores de arte da época tomaram o salão como a introdução do modernismo no cenário artístico catarinense.

As transformações urbanas nos aspectos sociais e culturais pelas quais passava a cidade serviam de estímulo para ele "compor seu arquivo, fotografar a cidade, pintar cenas de bar, do porto, das marinhas, da Praça XV." (BOPPRRÉ, 2006, p.31). A partir disso ele se lançaria numa sequência de quadros, dando sinais de sua futura investidura na linguagem videográfica. E foi na década de 1960 , atento às transformações de seu tempo, que Hassis se permitiu dessa vez, contar histórias a partir de câmeras $8 \mathrm{~mm}$ e uma super 8 , tornando-se pioneiro na produção de filmes em Florianópolis.

Esses aspectos da vida de Hassis confabulam com a ideia do homem que não se furtou experimentar o mundo e conduzem nosso olhar para o homem e sua obra. Seu trabalho não se acomodou em ver o mundo por uma única janela. Permitiu-se sentir e exprimir tudo que pode. Em seu acervo é possível encontrar obras de viés existencial, religioso, de crítica social, política, de iconografia do cotidiano etc.

A análise a seguir busca compreender a obra "Vento sul com chuva" (Figura 2), de 1957, a partir dos aspectos suscitados na imagem, interpretando os rastros deixados por Hassis para compreender 


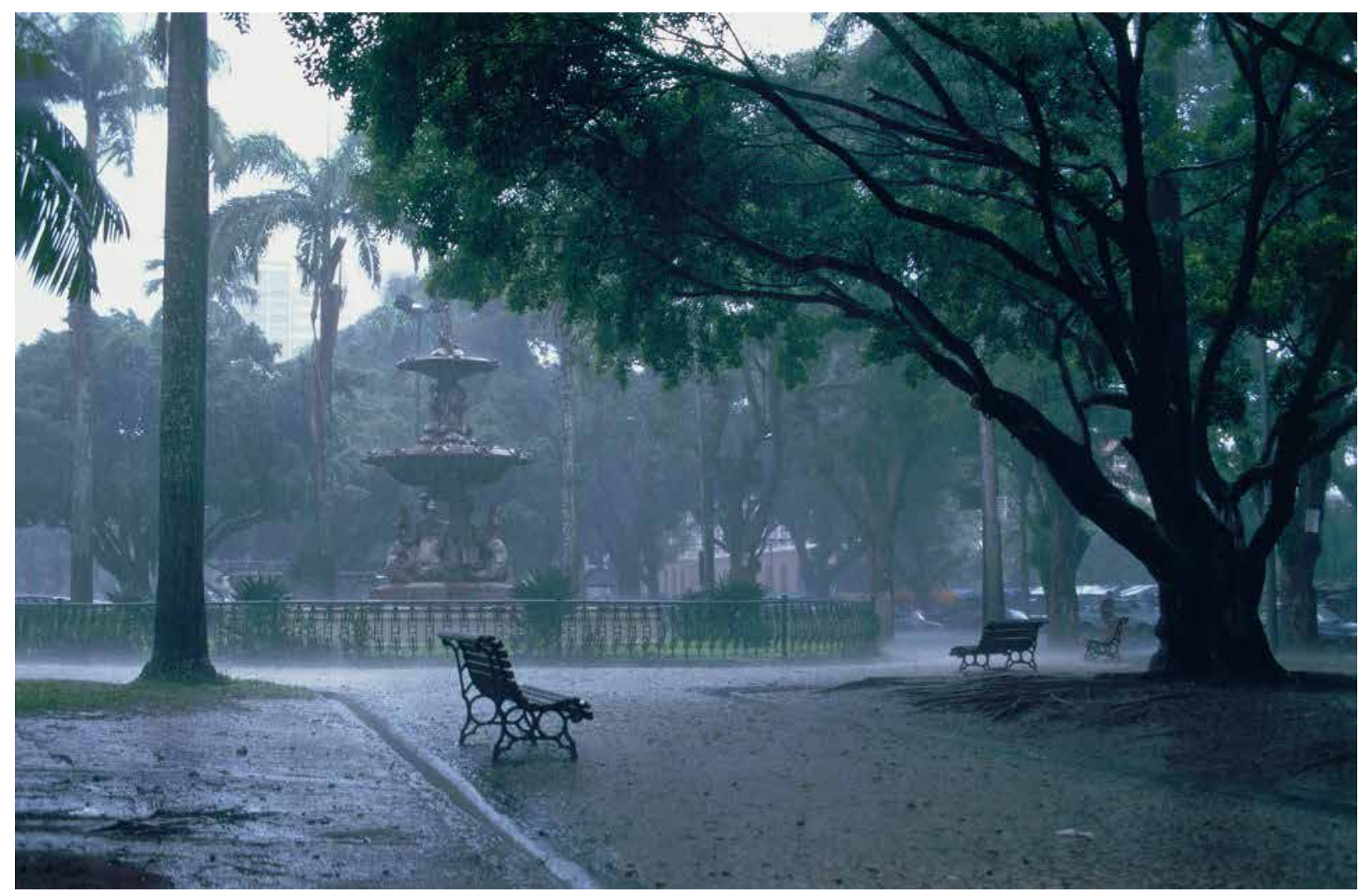

Figura 3 - Chuva na Praça da Sereia. Fotografia. Luiz Braga. 1995.

Fonte: Estúdio Luiz Braga.

seu percurso artístico como dialético, como também o próprio arquivo construído por ele, hoje, abrigado na Fundação Hassis, fundada e preservada por sua família após sua morte. Visto que do arquivo reverberam ainda muitos "Hassis" que permanecem ocultos, aguardando para emergir neste tempo presente.

Para se tentar compreender a imagem em questão e todas as articulações suscitadas por ela, no intuito de se constituir uma constelação de imagens que se ligam entre si, foi escolhida a fotografia "Chuva da tarde na Praça da Sereia" (1995) (Figura 3), do fotógrafo paraense Luiz Braga e o desenho "Guarda-chuva fechado" (Figura 4), do artista catarinense Susano Correia. Esta escolha, entretanto, não foi aleatória, mas surgiu de sinais que se acenderam na própria "Vento sul com chuva", despertando memórias, sensações e reflexões sobre essas relações.

Contribuem, pincipalmente, para esta análise as ideias de Walter Benjamin sobre imagem dialética, sobrevivência, constelações etc., refletidas por Didi-Huberman, e reforçadas por outros pesquisadores do campo da arte.

\section{VENTO SUL COM CHUVA - CONSTELAÇÕES E SINTOMAS}

\author{
"Vento sul suja, vento sul limpa" \\ "Noroeste na costa, Sul por resposta" \\ (ditos populares)
}

Ao entrar em contato pela primeira vez com a obra "Vento sul com chuva", de Hassis (1957), meu primeiro assombramento diante da imagem se deu por um lampejo de autorreconhecimento. De repente, a imagem suscitou-me a memória dos primeiros dias em que eu havia recém chegado à cidade de Florianópolis, em julho de 2017. Naquele momento, eu ainda nada sabia da cidade - de sua história, hábitos, costumes e fenômenos naturais -, quando fui tomada de surpresa e desprevenida, certo dia, por um forte vento gelado e uma chuva lateral que impactava feito gelo na pele, em uma larga avenida descampada, numa tarde de inverno. Lembro-me que a intensidade do vento, extremamente gelado, era tão forte que exigia de mim um esforço descomunal para manter meu andar em equilíbrio. Foi quando tomei conhecimento da existência do vento sul, e embora compreendesse 


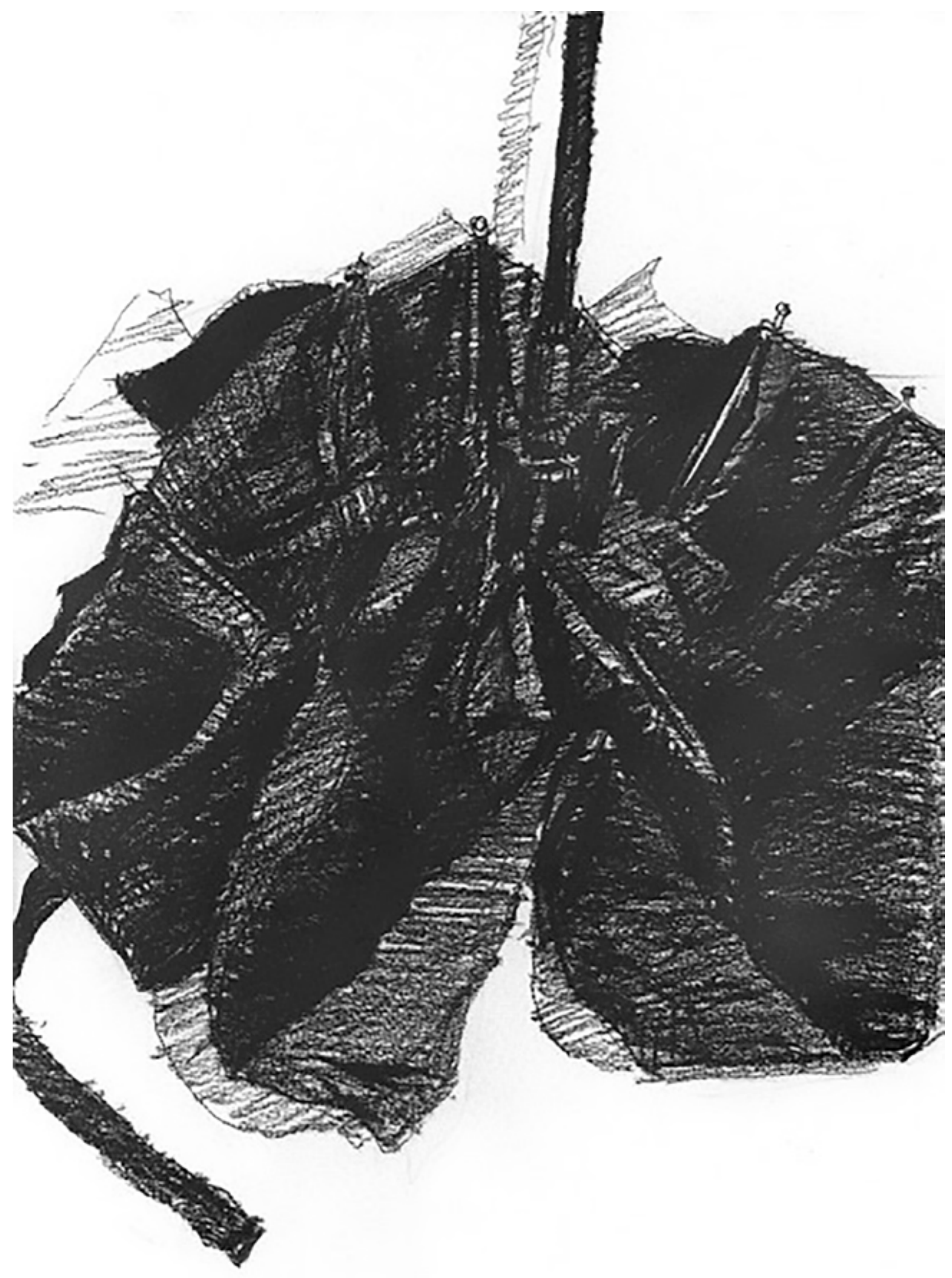

Figura 4 - Guarda-Chuva fechado. Carvão s/ papel. Susano Correia. Fonte: Site do artista. 
que se tratava de um fenômeno natural, até aquele momento, eu ainda não tinha ideia do quanto ele era representativo da cultura local e determinante de crenças e hábitos regionais.

Ao analisar a representação da paisagem nas obras de artes catarinenses, Makowiecky descreve a relação do vento sul com a cultura florianopolitana.

\begin{abstract}
"Apesar de não ser o mais frequente em Florianópolis, o vento sul é o mais relacionado com a história da cidade, chegando mesmo a fazer parte de sua cultura, por meio de mitos e lendas, da literatura, da música e nas artes plásticas. Ele é também o mais intenso e o mais frio, normalmente associado a chuvas. Gélido e uivante traz o cardume de tainhas no inverno, acaba com a praia num dia de verão, alimenta histórias de bruxas no interior da Ilha de Santa Catarina, forma hábitos, costumes e crendices de seus habitantes." (MAKOWIECKY, 2012, p.908).
\end{abstract}

Ao tomar conhecimento da importância do fenômeno do vento sul na cultura ilhéu, veio meu segundo reconhecimento: a de que também em Belém, minha cidade natal, tínhamos um fenômeno natural de semelhante efeito cultural na vida de seus habitantes: a típica "chuva da tarde", conhecida por cair sempre na hora do almoço ou no fim da tarde. Sempre torrencial e geralmente de curta duração (de dez a quinze minutos), chuva preguiçosa, é folcloricamente reconhecida como determinante dos hábitos belenenses, como por exemplo, agendar compromissos para "antes ou depois da chuva", sem definir precisamente a hora.

Esta breve introdução e paralelo sobre os fenômenos naturais tão característicos do cotidiano florianopolitano e belenense, sinaliza para o primeiro aspecto suscitado pela obra "Vento sul com chuva": as conexões e identificações que se articulam a partir da imagem; os lampejos dos quais nos fala Georges Didi-Huberman em Sobrevivência dos vaga-lumes (2011); a memória de um evento, cintilado na imagem no momento em que eu a compreendi em sua totalidade e que me fez apreendê-la em sua luminosidade. Talvez, a imagem não tivesse produzido o mesmo lampejo e eu não tivesse tido o mesmo assombro e percepção se não tivesse passado pela experiência viva anterior de ter me confrontado com o vento sul. Eis o motivo primeiro pelo qual a imagem me seduziu logo que eu a reconheci em minha própria experiência com o vento sul, pois entendo que é essa identificação que atualiza a obra e a faz ganhar novamente sentido no presente. A imagem então, sobrevive porque ativa constelações.

Se a imaginação - esse mecanismo produtor de imagens para o pensamento - nos mostra o modo pelo qual o Outrora encontra, aí, o nosso Agora para se liberarem constelações ricas de Futuro, então podemos compreender a que ponto esse encontro dos tempos é decisivo, essa colisão de um presente ativo com seu passado reminiscente. Deve-se sem dúvida a Walter Benjamin essa colocação do problema do tempo histórico em geral (DIDI-HUBERMAN, 2011, p.61).

Hassis, sempre em estado de alerta às características de seu tempo e lugar, sempre buscou traduzir em suas obras a "imaginária popular" (MAKOWIECKY, 2012). Preocupava-se com os aspectos sociais, mostrando o cotidiano da vida local. Assim, descreveu seu próprio trabalho: "A minha obra parte para aspectos sociais, mostra o homem em seu cotidiano, como marinheiro preocupado com o vento sul, a pressa do diaa-dia, os garotos trocando figurinhas [..]. Essas coisas todas que eu gosto." (HASSIS, 1999, apud MAKOWIECKY, 2012)

Tão significativo da vida cotidiana da ilha, o vento sul é muitas vezes mencionado quase que como um patrimônio pelos seus habitantes. Makowiecky ao escrever sobre a obra de Hassis, descreveu o sentimento e sensações do florianopolitano em relação ao vento sul:

E quem é da ilha, ou que aqui muito já viveu, sabe o que é o vento sul. Tomar contato com o vento, reconhecê-lo, identificá-lo, senti-lo, é algo que faz parte da alma florianopolitana. O nosso vento sul, inconstante e sutil, indiscreto, cruel e malicioso, que não perdoa os quem tem a petulância de o afrontar, seja quem for. (MAKOWIECKY, 2012, p. 2015).

Hassis captou em sua pintura as sensações provocadas pelo fenômeno quando ele nos toma de surpresa. O quadro conta uma história. Dado à narrativas, Hassis traduziu singularmente a força do vento, a agitação das pessoas lutando contra ele e contra a chuva fria. As cores, o movimento e o enquadramento - que nos remete a um instantâneo fotográfico ou a um frame de cinema-, fortalecem a narrativa. O artista congelou o tempo com suas tintas. As mesmas tintas que cintilam em minha imaginação, reacendem minha memória recente e fazem com que a obra também se acenda e ganhe novos significados no tempo presente. 
Se pensarmos no fenômeno do vento sul enquanto evento histórico e cultural junto aos habitantes de Florianópolis, podemos entender que "Vento sul com chuva" se configura como uma obra que dialoga com diversos tempos, inclusive o presente; questiona padrões e não encerra o passado em si. Ao contrário, esse passado é reatualizado a cada vez que rememorado por meio da imagem. Embora datada, não é necessariamente o tempo cronológico que a obra remonta, mas a percepção do próprio sujeito que se reconhece e se estranha, que estabelece conexões e seleciona, provocado pelo gatilho da imagem que também o provoca. Além disso, é uma imagem, e como tal, detentora de uma infinidade de possibilidades interpretativas. Nesse sentido, Walter Benjamin nos fala dessa imagem dialética, que embora percorra o passado, liberta a história de uma linearidade, por meio da rememoração: "Não é que o passado lance a sua luz sobre o presente ou o presente sobre o passado. Uma imagem, pelo contrário, é aquilo em que o Outrora encontra o Agora para formar uma constelação." (BENJAMIN, 1972, p. 577-578 apud CANTINHO, 2016). Sobre o assunto, Maria João Cantinho complementa:

Esta ideia da constelação é definida por Benjamin como a imagem dialética, como estado de suspensão da história: "a imagem é a dialética em suspensão. Porque, ao passo que a relação do presente com o passado é puramente temporal, a relação do Outrora com o Agora é dialética." (idem). Ela - a imagem dialética - faz deflagrar totalmente a relação temporal (no sentido cronológico) com o passado. A relação do passado com o presente é dialética, "imaginal" e, podemos ainda dizer, "só as imagens dialéticas são imagens autenticamente históricas, isto é, não-arcaicas. (CANTINHO, 2016, p.32)

Tanto Aby Warburg, como Walter Benjamin, concordavam com a ideia de imagem dialética, na qual a imagem carrega consigo a memória de carga potencialmente energética, rememorando experiências anteriores, destituindo a ideia de narrativa linear e contínua para entendê-la como "imaginal" ou figurativa e por isso constelar. É em termos metodológicos que eles vão se diferenciar: Warburg, segue o viés iconológico para recuperar e reconstituir a memória cultural do Ocidente por imagens. Em Benjamin, essa análise é feita procurando resgatar a memória histórica por imagens dialéticas $A$ analogia entre os dois autores reside, portanto, na ideia de que a reconstrução cultural se dá pelas associações e interpretações produzidas a partir da imagem, suas rememorações. (CANTINHO, 2016)

Para Didi-Huberman a imagem tem a capacidade de sobrevivência e de atravessamentos temporais, por isso se apresenta como rastros, vestígios. Para o autor, uma imagem se situa no trânsito entre o passado e o futuro e está carregada de tempos múltiplos:

Diante de uma imagem - não importa quão antiga -, o presente não cessa jamais de se reconfigurar, mesmo que o desapossamento do olhar tenha completamente cedido lugar ao hábito enfadado do "especialista". Diante de uma imagem - não importa quão recente, quão contemporânea ela seja -, o passado também não cessa jamais de se reconfigurar, pois esta imagem não se torna pensável senão em uma construção da memória, chegando ao ponto de uma obsessão. Diante de uma imagem, temos, enfim, de reconhecer humildemente: provavelmente, ela sobreviverá a nós, diante dela, nós somos o elemento frágil, o elemento passageiro, e, diante de nós, ela é o elemento do futuro, o elemento da duração. Freqüentemente, a imagem tem mais memória e mais porvir do que o ente que a olha. (DIDIHUBERMAN, 2015, p. 16)

Acompanhando o pensamento de Didi-Huberman, Makowiecky (2017, p.2068) entende que:

Ao aparecer, a imagem modifica completamente a temporalidade na qual se apresenta, pois seu sempre presente sem presença é inatual, é da ordem do retorno. É sem tempo na medida em que é, mas cuja presença abre o agora ao indeterminado. No tempo do fascínio, estamos submetidos aos poderes da imagem, aos tremores que pela distância nos seduzem e nos deslocam sempre para fora - e sempre dentro desse fora - na oscilação sem fim entre presença e ausência.

Que constelações "Vento sul com chuva" pode suscitar? Pensando na imagem como vestígios das memórias de Hassis e suas referências, remetome ao que a obra produziu em mim, colocando em operação meu próprio acervo, ativando minhas memórias de minha própria cidade natal, que, entretanto, se constitui de um tempo e espaço diferentes das experiências do próprio Hassis. É como se a imagem de "Vento sul com chuva" percorresse todo o tempo de Hassis, atravessando mundos distintos, para se articular com minhas próprias referências e experiências. Pensar por meio dessas referências fez emergir novas conexões imagéticas, através das quais pode-se articular uma pluralidade de sentidos opostos e semelhantes entre si. 
O sintoma seria o responsável por fazer aflorar memórias, relações, semelhanças e tensões com as múltiplas temporalidades que se manifestam nas imagens. Assim, a imagem de arquivo pode ser considerada como portadora de uma memória que Ihe é particular, dando espaço a uma montagem de tempos heterogêneos e descontínuos que, por sua vez, se conectam e se interpelam. (MELLO, 2014, p.21)

Para Flávio José Cardoso, segundo Makowiecky (2012), "Vento sul com chuva" se configura como uma forte referência plástica de grande força narrativa. Sobre a obra, ele escreveu as seguintes impressões:

\begin{abstract}
Raras vezes já se captou com igual felicidade um flagrante existencial da llha e nunca esse intemporal ilhéu que é o vento sul foi surpreendido numa tal vibração. Envolvidas vigorosamente nele, as pessoas que ali estão compõem um instantâneo de luta que remete o espectador à idéia de outras lutas. O vento lhe dá impulso, pensamento. Para lá vai a moça, atrapalhada em segurar a saia e a sombrinha; para cá vêm um homem cabisbaixo, às voltas com o imenso guarda-chuva, e um marinheiro lépido, a mão protegendo o boné. Se bem percebo, naquele ventaréu todo, moça e marinheiro arriscam um olhar, mas que vento! $\mathrm{Na}$ calçada, guarda-chuva fechado, uma capa que vem quase aos pés, um cidadão enigmático assiste às façanhas do vento e o corre-corre daquela gente, ou mastiga algum drama próprio? O vento está nessa pequena tela com a inteira força que vejo ali nas minhas árvores. (CARDOSO, 2001, apud MAKOWIECKY, 2012, p. 216) ${ }^{2}$
\end{abstract}

Articulam-se na obra elementos e gestuais marcantes do cotidiano do cidadão florianopolitano, caracterizando um sentimento de pertencimento das pessoas que se reconhecem nesse contexto específico. Sobrevivem nas imagens modos de vida; culturas, memórias. 0 vento sul está para os florianopolitanos como a chuva da tarde está para os belenenses.

Aqui está a semelhança: ambos os eventos naturais se constituem de uma identidade cultural em seus contextos locais. Nesse sentido, "Vento sul com chuva" se abriu como uma possibilidade constelar com a obra "Chuva da tarde na Praça da Sereia" (Figura. 3), fotografia do reconhecido fotógrafo paraense Luiz Braga. A foto emblemática da chuva da tarde belenense, retrata o fenômeno que também é determinante do modo de vida dos habitantes locais.

Embora a obra de Hassis seja pintura e a de Braga, fotografia, importa aqui ressaltar o quanto as imagens reativam memórias, atravessam-se e cruzam os tempos retidos nelas. E, que "Chuva da tarde na Praça da Sereia" só emergiu no contexto desta análise pelo gatilho invisível disparado no momento em que apreendi "Vento sul com chuva", operando sobre minhas próprias experiências e memórias, ainda que deslocadas histórica e geograficamente do contexto da obra de Hassis. Neste sentido, Makowiecky ressalta que:
"As grandes questões humanas sobrevivem nas imagens, é através delas que se conhecem outras culturas, outros povos, e é na imagem, imagem como noção operatória e não como mero suporte iconográfico, que aparecem as sobrevivências, anacrônicas, atemporais, memórias enterradas e que ressurgem." (MAKOWIECKY, 2012, p.909).

As imagens também revelam contradições entre si: na pintura de Hassis percebe-se um ritmo, uma dinâmica diferente do que se pode observar na fotografia de Braga. Figuram as pessoas na pressa cotidiana, percebe-se a agitação da vida que segue na luta, mesmo com o vento sul. $A$ foto de Braga tem outro tempo e uma ausência. Não há indícios de transeuntes na rua. Sob a chuva quente e torrencial, paira uma calmaria e certa melancolia na imagem. Também não há vento, a árvore escorre. As pessoas estão resguardadas, esperando a chuva passar para retomar a vida. Assim é Belém quando cai a chuva. As contradições também as atualizam. São imagens dialéticas, porque estão histórica e socialmente situadas, mas que se atualizam constantemente e assim, sobrevivem ao tempo.

Para fechar esta análise e o conjunto constelar suscitado por "Vento sul com chuva", provoco trazendo o desenho "Guarda-chuva fechado" (figura 4), de Susano Correia. A obra constava sem data no site do artista.

Nascido em Florianópolis, Susano é artista visual. Trabalha principalmente com desenho e pintura. É um artista que se interessa especialmente por questões existenciais da condição humana. Sua obra é carregada de expressividade e dramaticidade nas formas. "Guarda-chuva fechado" se liga às duas imagens anteriores pela sua simbologia: o guardachuva. Mas é também atraído para esta constelação de imagens por sua expressividade. No imaginário que se constrói a partir de sua representação, tem-se que sua forma desalinhada e amassada, dá indícios de já ter sido bastante usado, seja para se proteger do vento sul com chuva ilhéu, seja da chuva torrencial da tarde belenense. 
Percebe-se que a rede constelar formada aqui, articulada a partir de "Vento sul com chuva" não se constitui de similaridades estéticas. Se existe alguma semelhança entre as imagens, esta se dá no campo subjetivo. Entretanto, encontram-se imbricadas de significados que se evidenciaram a partir de suas interrelações.

"Guarda-chuva fechado" sem articulação com este contexto não pode ser lido de forma igual como quando se configura nessa teia de interpretações. Como imagem indiciária de outros contextos, como quando articulado com "Vento sul com chuva", por exemplo, sua capacidade expressiva e potencialidade visual ganham força. A imagem não cessa de atualizar em nosso imaginário, de buscar cada vez mais novas conexões.

Podemos pensar o guarda-chuva em sua frágil estrutura para estabelecer analogias com 0 existencialismo humano; da mesma forma, podemos imaginar a melancolia constante na fotografia de Luiz Braga ou na sua inutilidade, diante da força do vento sul, narrado por Hassis. Estamos sempre procurando por esses sinais que legitimem nossa experiência com as obras. As imagens não param. Pensamos por imagens.

Entendendo que a imagem de arquivo ganha status de memória por acumular fragmentos de tempos distintos, este então, deixa de ser mero objeto para operar como pensamento. "Vento sul com chuva" apresenta-se aqui como um documento vivo e incontestável do tempo de Hassis. Com todos os seus indícios, materiais e simbólicos, ela se configura como vestígio do que foi e continua sendo Hassis. Sua sobrevivência ocorre por engendrar novas narrativas, possibilitar novas interpretações e por se vincular de forma cúmplice a outras imagens.

Desta forma, tomar a obra de Hassis, tendo como ponto de referência seu imensurável arquivo, demanda considerá-la uma imagem sobrevivente. E ainda que a obra deixasse de existir, havendo ainda o arquivo, haveria Hassis.

As obras de Hassis tem um significado expandido a partir do seu arquivo. Este por sua vez também ganha significados novos. Para além de seu potencial documental, o arquivo de Hassis movimenta o imaginário, ele não atesta apenas o que é real e concreto, mas também o invisível e imaterial articulados por Hassis em suas obras. Um arquivo se configura como um processo carregado de potencialidades sempre em devir, que não se atém em um tempo cronológico, mas produz incessante reconfiguração do passado e cuja carga crítica e histórica é determinante de sua característica dialética.

Hassis confrontou seu tempo com sua arte. Embora autodidata, nunca esteve à margem. Pesquisava e produzia incansavelmente, segundo ele mesmo narrou em entrevistas. Adotou uma arte de expressiva narrativa para falar de sua cidade, de questões sociais, problemas existenciais e de si mesmo. Era um inconformado e agradecia por nunca haver se encontrado, pois este era o seu mote: sempre buscar.

Pensar por meio da obra de Hassis me possibilitou articular mundos distintos, contrapor realidades, encontrar situações tão análogas, quanto distintas, e me fez refletir como nosso pensamento e nossas memórias sobrevivem por imagens. Pensar através de "Vento sul com chuva" me deu a dimensão do meu deslocamento espaço-temporal entre as duas cidades, Belém e Florianópolis; localizou-me historicamente, culturalmente e geograficamente; fez-me reconhecer traços de identidade e de identificação que, certamente, atualizam-se e reconfiguram-se continuamente, formando novas conexões e assim, engendrando constelações, e assim, atualizando também a própria imagem contida na obra de Hassis.

\section{NOTAS}

01. Fonte: Site da Fundação Hassis. Disponível em: http://www.fundacaohassis.com.br. Acesso em: 20 jul. 2008.

02. Trecho do livro Do livro "Senhora do meu Desterro", Florianópolis, Lundardelli / Fundação Franklin Cascaes, 1991).

\section{REFERÊNCIAS}

ARA: JO, A. M. Mito e Magia na Arte Catarinense. Tese. Curitiba: UFSC, 1977. p.211-255.

BOPPRE, F. C. Hassis: um tempo cuidadosamente recolhido e organizado. In: FLORES, M. B.R.; 
LEHMUKUHL, L.; COLAÇO, V. (orgs.) A casa do baile: estética e modernidade em Santa Catarina. Florianópolis: Fundação Boiteux, 2006, p.375-395.

BORGES, V. T. “Enquanto eu viver, enquanto eu respirar": os registros orais de Hassis, investigando um arquivo autobiográfico. História Oral, v. 14, n. 1, p. 37-48, jan.-jun. 2011.

CANTINHO, M. J. Aby Warburg e Walter Benjamin: a legibilidade da memória. História revista., Goiânia, GO, v. 21, n. 2, p. 24-38, maio/ago. 2016.

CHEREM, R. M. O arquivo e suas imparidades. In: Encontro da Associação Nacional de Pesquisadores em Artes Plásticas. 25), 2016. Porto Alegre, RS. Anais do 25) Encontro da ANPAP: Arte: seus espaços e/em nosso tempo. Porto Alegre: ANPAP, Universidade Federal do Rio Grande do Sul, 2016. p. 1199-1214.

DIDI-HUBERMAN, G. Sobrevivência dos vagaIumes. Belo Horizonte: Editora UFMG, 2011.160p.

G. Diante do tempo: história da arte e anacronismo das imagens. Tradução Vera Casa Nova, Márcia Arbex. Belo Horizonte: Editora UFMG, 2015.

KAMMERS. E. G. Entre o moderno e o tradicional - A Florianópolis da década de 1950 nas pinturas de Hassis. In: Encontro Nacional de Estudos da Imagem, II, 2009. Londrina, PR. Anais do II Encontro Nacional de Estudos da Imagem. Londrina: UEL. 2009. p.418-426.

MAKOWIECKY, S. A representação da cidade de Florianópolis na visão dos artistas plásticos. $1^{\text {a }}$. ed. Florianópolis: DIOESC- Diretoria da Imprensa Oficial e Editora de Santa Catarina, 2012. v. 1. $474 p$.

S. Paisagem imaginada, representada e capturada: Florianópolis e o vento sul. In: Colóquio do Comitê Brasileiro de História da Arte, XXXII, 2012. Brasília, DF. Anais do XXXII Colóquio do CBHA: Direções e Sentidos da História da Arte. Campinas: Comitê Brasileiro de História da Arte - CBHA, 2013 [2012]. p. 945-964.

S. Janelas múltiplas, janelas do olho, espírito da alma, espelho do mundo, In: Encontro da Associação Nacional de Pesquisadores em Artes Plásticas, 26), 2017, Campinas, SP. Anais do $26^{\circ}$ Encontro da ANPAP. Campinas:
Pontifícia Universidade Católica de Campinas, 2017. p.2056-2083.

MELLO, J. G. de O. Arquivo como sintoma: Anacronismo das imagens na obra de Harun Farocki. Revista Passagens, Programa de Pósgraduação em Comunicação UFC, Fortaleza, CE. v. 5. N. 1. p. 20-34. 2014. PDF. Disponível em: <http://www.periodicos.ufc.br/passagens/article/ view/1347/1262>. Acesso em: 25 jul. 2018.

\section{SITES}

FUNDAÇÃO HASSIS. Disponível em: <http://www. fundacaohassis.com.br>. Acesso em: 20.08.2007.

NOTAS VISUAIS/ SUSANO CORREIA: <http://www. notasvisuais.com/2012/11/>. Acesso em: 25 jul. 2018.

SUSANO CORREIA. Disponível em: <https://www. behance.net/susanocorreia>. Acesso em: 25.08.2018

\section{SOBRE A AUTORA}

Cláudia Silvana Saldanha Palheta é discente do curso de Mestrado em Artes Visuais, na linha de Ensino de Artes da Universidade do Estado de Santa Catrina. Graduada em Educação Artística pela Universidade Federal do Pará com habilitação em Artes Plásticas. Especialista em Semiótica e Artes Visuais pelo Instituto de Ciências das Artes (ICA)/ UFPA. Especialista em Educação Especial pelo Instituto Superior de Educação de Afonso Cláudio (ISEAC). Professora de Artes Visuais com atuação na Educação Especial, trabalhando na APAE de Belém. Tem experiência na área de arte-educação, com ênfase em Artes Visuais e também na área de Educação Especial, com ênfase no ensino de Artes Visuais. Colaboradora do Grupo de Estudos em Educação Inclusiva e Ambiental (GEIA) do Instituto de Ciências Biológicas da Universidade Federal do Pará, pesquisando arte como ferramenta transdisciplinar na educação de pessoas com deficiência intelectual e desenvolvendo atividades em colaboração com os estagiários do grupo (2016/2017). Atualmente, cursa o mestrado em Artes Visuais do Programa de Pós-Graduação em Artes Visuais (PPGAV / UDESC) e integra o Grupo de Pesquisa Educação, Artes e Inclusão, da Universidade do Estado de Santa Catarina. 